manswas

glyndwhr

Glyndŵr University

Glyndŵr University Research Online

Social Inclusion Research Unit

Social and Community

$1-1-2004$

\title{
Missing links? Problem drug use and social exclusion
}

Julian Buchanan

Glyndwr University, julianbuchanan@gmail.com

Follow this and additional works at: http://epubs.glyndwr.ac.uk/siru

Part of the Community Health Commons, Public Health Commons, and the Substance Abuse and Addiction Commons

The difinitive version is available at www.blackwell-synergy.com Follow this link www.blackwellsynergy.com

\section{Recommended Citation}

Buchanan, J. (2004) 'Missing links? Problem drug use and social exclusion'. Probation Journal,51(4), 387-397

This Article is brought to you for free and open access by the Social and Community at Glyndŵr University Research Online. It has been accepted for inclusion in Social Inclusion Research Unit by an authorized administrator of Glyndŵr University Research Online. For more information, please contact d.jepson@glyndwr.ac.uk. 


\title{
Missing links? Problem drug use and social exclusion
}

\author{
Julian Buchanan, University of Wales, NEWI, Wales
}

Abstract In the late 1980s illicit drug use became a major social problem in the UK. Since then policy and practice has largely been shaped by psychological and medical perspectives that emphasise the physiological and psychological nature of dependence. Concerned by the limited impact in reducing the number of problem drug users, in 2000 the Government shifted the emphasis away from voluntary treatment by the Health and Voluntary sector, towards coercive treatment, initially in the form of a Drug Treatment and Testing Order (DTTOs). The Criminal Justice Interventions Programme (CJIP), a £447m programme to 'direct drug misusing offenders out of crime and into treatment' (Home Office, 2004 p. 29) further illustrates and reinforces this shift. This article argues that this shift in approach is also likely to founder, as it continues to be dominated by a narrow focus on the individual and their drug dependence, and fails to adequately address the social context, nature and underlying causes of problem drug use.

Keywords Drugs, Social Exclusion, Addiction, Treatment, Crime, CJIP

\section{Dominant theoretical frameworks}

UK policy and practice has largely been shaped by three key theoretical frameworks; Harm Reduction, Motivational Interviewing and the Cycle of Change. These approaches emphasise the physiological and psychological nature and consequences of dependence. Harm Reduction was promoted by the Advisory Council on the Misuse of Drugs (ACMD, 1988) on the basis that HIV posed a greater threat to society than drug use itself. It was argued that in order to develop relationships with the drug-using community and encourage safer practices to protect the spread of infection to the non-drug-using population, agencies had to be prepared to accept continued drug use and offer accessible user friendly services. This involved the supply of free, clean needles and syringes, free condoms and maintenance-prescribing of substitute drugs and was supported with health promotion literature that gave drug users the 'facts' about drug use to enable them to make rational choices. Harm reduction was reluctantly and pragmatically embraced as agencies felt obliged to protect the non-drug-using population from the risks posed by the drug using population (Riley \& O'Hare, 2000). However, as the incidence of HIV across the general population did not escalate as feared, the prominence and practice of harm reduction receded in the UK and across many EU countries (European Monitoring Centre For Drugs And Drug Addiction, 1999). Nevertheless, the UK, a pioneer of harm reduction, still largely embraces the principles of engaging with drug users to reduce risk and harm, though many aspects of harm reduction, such as needle exchanges, prescribing injectable drugs and maintenance substitute prescribing, remain controversial and lack sufficient support and are not widely available across the UK.

At the same time that harm reduction was promoted, psychologists in the early 1990s developed motivational interviewing techniques to help engage drug users more openly and realistically. Rather than pressurising or persuading them to become drug free by presenting an overwhelming list of risks and dangers, motivational interviewing seeks to empower the drug user by assisting and facilitating a process that will enable them to reflect upon their own situation as they perceive it (Miller \& Rollnick, 2002). It is all too easy for workers to impose a rationale for change along with a treatment plan that eventually sets the drug user up to fail. Motivational interviewing has helped to counter act this problem by involving drug users in a dialogue that explores the negative as well as the positive aspects of their dependence. Crucially, it can be used to help the drug user examine their current situation openly, from their frame of reference, without any hidden agenda from the worker, though the quality and effectiveness of this approach is dependent upon the knowledge, skills and integrity of the worker. This exploration of the drug habit and lifestyle as determined and assessed by the drug user can help to create an internal conflict which can lead to greater clarity of purpose, and genuine self-motivation to bring about change.

The third influential framework that has complemented harm reduction and motivational interviewing is the Cycle of Change (Prochaska et al., 1992) which was originally developed in the 1980s for cigarette smokers. This model suggests that people who struggle with dependent behaviour can be located in one of six stages; pre-contemplation, contemplation, action, maintenance, termination or relapse, and by identifying which stage a the person is at enables a more appropriate and effective response to be offered. For example, if it can be established the person is in a pre-contemplation stage (when they can't see, don't see, or will not see that they have a drug problem) then a goal setting approach (action phase) is likely to be a counter productive. The strength of this psychological approach is that it usefully provides a framework for appropriate and constructive engagement with problem drug users regardless of what stage they are at, rather than insisting drug users need to ready and committed to a drug free lifestyle before meaningful can take place. The model also accepts the inevitability of relapse and uses relapse as a constructive opportunity for learning.

These three theoretical frameworks, established in the early 1990s, have dominated work with drug users. They helpfully promote the important psychological and physiological components of dependence, but tend to lack recognition or appreciation of the social components of dependence, such as structural inequality and discrimination, which so often precede problem drug use, and later act as a major barrier making it difficult for problem drug use to break out from a drug centred existence. These three domin ant theories have nevertheless positively contributed and influenced policy and practice in the UK, but there is a danger that used in isolation from a social understanding, these theories may inadvertently pathologise problem drug use by narrowing the focus and attention towards the individual, their choices and their motivation for change.

\section{Taking legal steps to tackle problem drug users}

In the late 1990s a marked shift in drug treatment occurred when service provision for problem drug users in England and Wales became more closely aligned with the criminal justice system. In October 2000 the government introduced Drug Treatment and Testing Orders (DTTOs). This established new levels of coercion and monitoring - it required problem drug users to be urine tested frequently, and to have their progress regularly reviewed by the Court. This has subsequently been followed by further measures contained in the Criminal Justice Interventions Programme (CJIP) plans aimed at tackling drug use among offenders. This three-year programme which started in, 2003 has $£ 447 \mathrm{~m}$ available to integrate measures for 'directing drug misusing offenders out of crime and into treatment' (Home Office, 2004 p. 27). These new arrangements have led to the creation of Criminal Justice Integrated Teams (CJITs) within Drug Action Teams (DATs) to provide a case management approach that will enable throughcare arrangements to provide a continuity of care for drug misusers from the very beginning to the very end of their time in the criminal justice system. 
This new fusion in which drug treatment is monitored and delivered through correctional agencies raises issues concerning assessment, motivation, and appropriate referral, as well as ethical issues. This coming together is likely to further strengthen the focus upon individual choice and change concerning illicit drug use. The Health Service primarily concerned with reducing physiological risk and harm, treats people as responsible adults who can be empowered with adequate information to make informed choices. In relation to problem drug use it provides: needle exchanges, prescribing services, promotion of safer practices, information services, detoxification units, Hepatitis and HIV prevention measures etc. Whereas, correctional agencies will promote coercive measures to direct, monitor and enforce treatment, with the underlying threat of sanctions for any failure to cooperate. Through the criminal justice system a range of measures are now available for drug using offenders including; Drug Treatment and Testing Orders (DTTOs) with court reviews, regular drug testing, Counselling, Assessment, Referral, Advice/Information and Throughcare in prisons (CARATS), Abstinence Orders, Anti Social Behaviour Orders (ASBOs) Community Rehabilitation Orders (CROs) with conditions etc.

In respect of drugs, the Health sector agencies and correctional services are both committed to tackling drug dependence, and reducing the risk and damage of drugs to the individual, and particularly to wider society. This combined Health/Crime ap proach focuses largely on drug dependence and pays limited attention to the underlying causes of long term problem drug users, nor to the social context within which problem drug use takes place, although the introduction of regional rehabilitation strategies led by the new Regional Offender Managers under the new National Offender Management Service intends to 'increase joint work with key stakeholders in order to establish innovative packages which facilitate access to the mainstream services for offenders, whether they are serving sentences in the community or have just been released from custody' (Home Office, 2004a p. 8). Figure one illustrates how problem drug use is then generally framed and understood by its nature and impact in respect of three key components; Health, Legal and Psychological.

Figure 1. Understanding problem drug use - the traditional framework

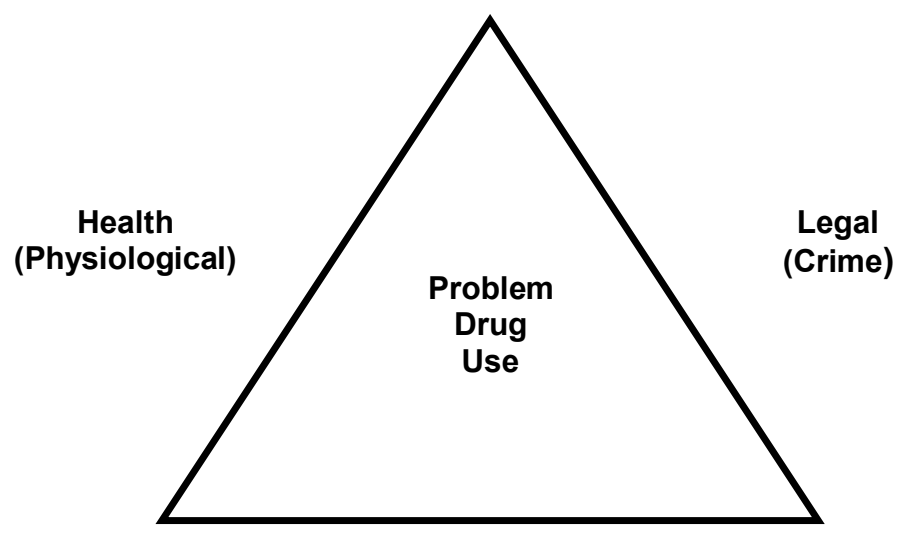

Psychological

This model places the focus upon the drug, rather than the drug users and their social context. It risks pathologising problem drug users by holding them solely responsible for exercising poor choices and allowing themselves to drift into drug addiction. The physiological health approach is largely concerned with promoting healthy lifestyles. With a tendency to promote pathological notions of dependence such as the addictive personality, and to embrace the view that problem drug use warrants no sympathy because it is a self inflicted condition. Technically problem drug use could be seen as a self inflicted and the result of poor choices, but these choices have been influenced by a range of powerful negative pressures and aggravating factors that have limited and diminish the alternatives and opportunities available to this section of society.

The psychological approach risks decontextualising problem drug users, suggesting dependence can largely be controlled by internal adjustments in thinking, motivation, or the development of cognitive behavioural techniques. The legal approach rightly emphasises the cost and damage caused by problem drug users to wider society. It promotes enforcement, coercion and close monitoring through a variety of legal sanctions, such as the Drug Treatment and Testing Order to ensure problem drug users access treatment and change behaviour.

What this framework fails to acknowledge is that for many, not all, problem drug use is largely a socially constructed phenomenon that has less to do with individual choice or physical dependence, and much more to do with the structural disadvantages, limited opportunities, alternatives and resources. The evidence for this assertion will be examined in the remainder of this article. However, by concentrating on their drug taking rather than the social context and underlying causes of their dependence, there is a risk of wrongly thinking that positive and constructive lifestyle changes can be achieved once the person is drug free and has overcome their physical and psychological drug dependence.

For a significant majority of long term problem drug users (a group that are rapidly filling the prisons in the UK and the USA) drugs are not the real problem - if anything drug taking for this group can best be understood as a rather obstructive solution to a deep seated underlying socio-economic problem that has disproportionately affected a significantly majority of problem drug users. This article will demonstrate that many problem drug users have limited opportunities to exercise choice and many have endured severe disadvantage and social exclusion prior to developing a drug problem.

If the social context is significant to any understanding of problem drug use then an alternative framework to understand and respond to problem drug users is needed. One that incorporates a social understanding of a drug centred lifestyle, and acknowledges the impact of disrupted childhoods, relationship breakdowns, educational under achievement, low self esteem, unemployment, physical and sexual abuse. 
Figure One: Understanding problem drug use - incorporating a social dimension

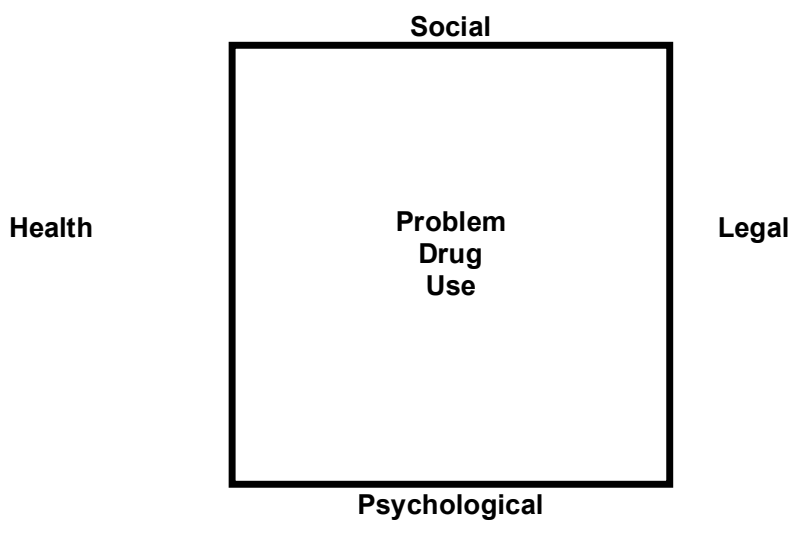

\section{The social dimension to problem drug use}

There is growing evidence that social disadvantage and social exclusion are important factors that tend to precede problematic drug use (SEU, 2002; Home Office, 2004). Drawing upon a range of different studies it is possible to tentatively identify some common antecedents in the social exclusion - drugs/crime - social exclusion trap. By no means a comprehensive trawl of research available, the studies below do nevertheless, provide some valid and interesting correlations. Drawing upon the findings from these studies it is possible to build an initial profile of the common social factors concerning problem drug users.

- A survey of 550 clients views on drug services carried out by Addaction (Jones et al., 2004)

- A survey of 1, 884 males in 2000 who had recently been sent to prison (Liriano \& Ramsay, 2003)

- A survey of 529 male prisoners in 2000 (Bullock, 2003)

- The Social Exclusion Unit (SEU) Report Reducing re-offending by ex-prisoners (SEU, 2002)

- A survey involving 200 problem drug users on Merseyside (Buchanan \& Young 2000)

The SEU states that 'Problematic drug users tend to be members of the most deprived and socially excluded communities' (SEU, 2004 p. 11). This may appear an inevitable outcome for anybody whose life has been centred upon drugs, however, the findings from these various studies indicate that for a significant proportion of clients exclusion and disadvantage were major issues prior to the onset of a drug habit.

The average age of problem drug users in contact with agencies is around $28-32 \mathrm{yrs}$, with an onset of drug experimentation between 16 -18yrs old (Buchanan \& Young, 2000 \& Jones et al., 2004) suggesting a drug problem that stretches back well over a decade. But most significant is that many of these problem drug users suffered serious social disruption prior to the onset of drug taking. In the Addaction Study involving 550 clients 1 in 5 had been in care as a child, and $64 \%$ had been in prison (Jones et al., 2004). Bullock's survey (2003) involving 529 male prisoners, found three quarters admitted to being drug users, with an even higher proportion having been taken into care as children - $32 \%$.

In terms of education over half (54\%) had been excluded from school (Jones et al., 2004), over half (52\%) never completed their statutory education and didn't possess a single academic or vocational qualification (Buchanan \& Young, 2000). Liriano \& Ramsay, 2003 study of 1,884 men in prison found that $73 \%$ were drug users, $59 \%$ didn't posses an educational qualification. Of the remaining $41 \%$ that did posses a qualification, not one had achieved an A level or degree level qualification. The percentage of children that leave school without a qualification is very low (around 6\% according to the DfEE), so these children appear to be disproportionately represented amongst the problem drug using population The Social Exclusion Report on rehabilitating prisoners highlights the struggle that this client group face in securing employment;

'Low skills feed into low employability, with only half of prisoners having the reading skills, one-fifth the writing skills and less than one-third the numeracy necessary for 96 per cent of all jobs' (2002 p. 53)

Not unexpectedly which such a difficult start to life unemployment was an almost inevitable outcome with $14 \%$ of problem drugs users having never worked, and $54 \%$ having been unemployed for more than 5 years (Buchanan \& Young, 2000). Eleven percent of prisoners were unable to work due to illness and or disabilities (Liriano \& Ramsay, 2003), while Bullock found that $60 \%$ of the prisoners were unemployed prior to custody. 62 per cent of short-sentenced male prisoners involved in drug misuse said that they had spent more time unemployed than in work (2002 Social Exclusion Unit).

There will be exceptions to the rule. Such is the complexity of human behaviour, there will inevitably be a proportion of people who endure the very same inequalities and disadvantages, yet do not go on to develop a drug problem or commit crime. Indeed, it would be misleading to suggest that all problem drug users had disadvantaged and damaging childhoods, but the overall pattern of disproportionate disadvantage does emerge. Based on these studies it becomes clear that compared with the wider population problem drug users are much more likely to have suffered difficult childhoods, more likely to have been in care, to have struggled in formal education, failed to achieve qualifications, found employment hard to come by, and taken illicit drugs and committed crime. There will be other possible common social factors that are missing from this initial trawl of research literature which will usefully provide further relevant insights into the shared experiences of problem drug users, such as; physical and/or sexual abuse, poverty, unemployment, mental health problems and a family history of problem drug use. 
This correlation between problem drug use and social exclusion does not indicate a monocausal relationship between structural disadvantage and problem drug use, however, the evidence (and indeed practice wisdom) suggests that some connections do exist, and when working with this client group these factors must form an important part of the assessment and intervention strategies. When considering treatment and rehabilitation it must be recognised that many problem drug users have had such limited options in life, that they lack personal resources (confidence, social skills and life skills) and have limited positive life experiences to lean upon or return to. This client group need social integration not social re-integration, they need habilitation not re-habilitation - it seems that many have never really been able to get started in life in the first place. This makes living without drugs a very tough option indeed.

\section{Demonising illicit drug use}

It is clear then many problem drug users have experienced social exclusion and disadvantage prior to drug taking. For this group the onset of excessive drug taking in early adulthood may be a form of escape when there appears to be no legitimate way of accessing what appears to be widely available to the rest of society. In this sense social exclusion has led to problem drug use. Problem drug use does however, lead to further social exclusion as drug users become subject to 'othering' - presented as if they are somehow different to the majority in society (who prefer legalised recreational drugs such as alcohol and tobacco). Yet ironically and hypocritically, compared to some illicit drugs, alcohol and tobacco are potentially more dangerous substances and some of the most serious risks from illegal drugs are caused by their illegality. This othering of illicit drug users is reinforced and institutionalised as the government portrays problem drug users as a menace to society, and seeks to protect 'us' from the dangers 'they' pose. The emotive language of war and fear is evident in an H M Treasury Press Release (2001) which issued new money to 'fight' drugs

\footnotetext{
'...hardly a family is unaffected by the evil of drugs... Drug-related crime blights our communities. It destroys families and young lives and fuels a wide range of criminal activity, including burglary and robbery..... We won't tolerate the menace of drugs in our communities - it causes misery and costs lives... This new money will enable agencies to step up their fight against drugs and the crime it breeds. It will get drug dealers off our kids' backs and into prison and help safeguard our communities'
}

The war against drugs all too easily evolves into a war against drug users (Buchanan \& Young, 2000) which only further marginalises those with drug dependency difficulties. So problem drug users who prior to a career in drugs, struggled to make the transition from childhood to adolescence, then struggled to make the transition from adolescence to adulthood, find themselves portrayed as an 'enemy within'. Being the focus of further hostility has repercussions on the way the see themselves, their relationships within their families, and with wider communities. Drucker suggests the repercussions they face as a result of this demonisation and criminalisation could be a greater threat than the dangers posed by the drugs they take;

'In an environment frightened with powerful moral and legal reactions to the use of drugs, the stigma attached to drugs may come to be a more important factor than the biology of addiction. The demonization of drugs and the criminalization of the drug user (i.e. the war on drugs) could be more damaging to the individual and society than drug use or addiction.' (Drucker, 2000:31)

The discourse dominated by notions of fear and war, inevitably leads to an underlying strategy concerned with punishment, con trol and exclusion of drug users; rather than care, rehabilitation and inclusion. This attempt designed in part to deter people from trying illegal drugs, has resulted in widespread discrimination, so that in addition to overcoming a drug problem, one of the biggest hurdles problem drug users face is breaking through the barrier of social exclusion, prejudice and discrimination. The constant experience of this marginalisation has led many problem drug users to internalise their problems and blame themselves for their plight. This loss of selfesteem then becomes a serious debilitating factor as they feel isolated and excluded from society.

For many problem drug users relapse is not simply the result of physical craving or a lack in motivation, but it is a direct consequence of a frustration and inability to secure a position in normal community life and establish everyday routines. The demonisation of problem drug users makes it unlikely for individuals and agencies to 'give them a chance' and as a result they find themselves regularly shunned and excluded. At the very time when recovering drug users need assistance and support from the non drug using population to establish alternative patterns of social and economic life they are often prevented by the wall of exclusion (see diagram below).

Figure 3. Steps to Reintegration*

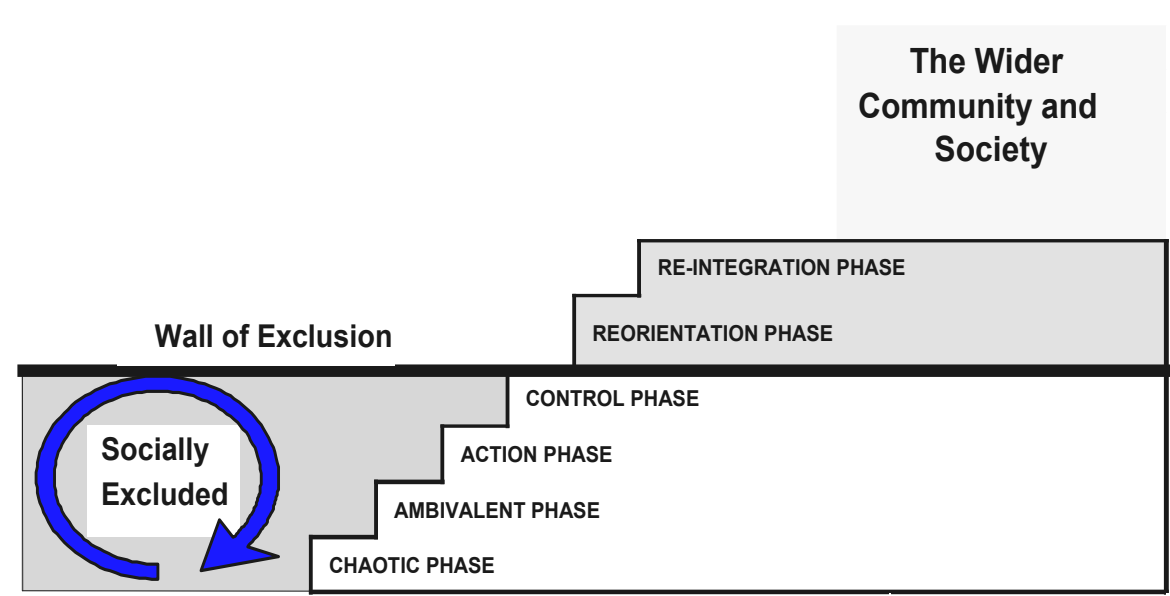

The Steps to Reintegration model adapted from the widely understood Prochaska et al., (1992) Cycle of Change promotes the importance of social reintegration and highlights the struggle of problem drug users trying to break through the wall of exclusion. Indeed, it could be argued the main cause of relapse is the struggle for social reintegration. It is a struggle to secure a new identity, the 
difficulty in finding acceptance among the non drug using population, the challenge of developing new habits and routines, of acquiring a new focus; these are all key aspects of the Reorientation phase. The final phase is to begin social reintegration within wider society. This may involve; finding accommodation, employment, securing a place in further education or establishing basic daily social routines such as picking up children from school, shopping, cooking, going to the cinema etc. For many recovering long term problem drug users who have been immersed in a drug centred lifestyle for their entire adult life, these basic routines can be a real challenge. A more detailed explanation of the steps to reintegration can be found elsewhere (see Buchanan forthcoming 2005).

The majority of drug services concentrate their efforts on addressing the needs of problem drug users below the line of exclusion, whereas, there is a need to develop more drug services concerned with reorientation and reintegration phases - services that specifically appreciate and address the fact that many long term problem drug users have no previous drug free adult life to recall, or return to. Drug services that are geared towards assisting with reorientation and reintegration could include: befriending schemes, buddying programmes, mentoring schemes, structured day programmes, sheltered work programmes, voluntary work, basic adult education etc. There is a steady growth of such schemes emerging across the UK, though generally the issue of social integration and problem drug use receives limited attention. There are also a growing number of government initiatives designed to tackle 'hard to reach groups' or 'persistent offenders' or 'prolific' offenders (DfES, 2003) which will hopefully embrace a social understanding of problem drug use. However, these are largely reactive responses to the symptoms of social injustice and will need to be complemented by policies and practices that acknowledge and address the causes of the problem.

\section{Conclusion}

A disproportionate number of problem drug users have been disadvantaged and socially excluded prior to taking drugs. For many the all-consuming drug-centred lifestyle is the only adult existence they have known and should be seen as an inappropriate solution, rather than the problem itself. Discourses then that emphasise the importance of physiological and psychological aspects of drug dependence are struggling to have impact because they take little account of the underlying social context of problem drug use. Directing drug users into treatment through the criminal justice system with court orders and license conditions is likely to have little long term impact unless the social inequalities are acknowledged, understood and addressed. There has been a tendency to concentrate on the drug problem, and see harm reduction and physical/psychological dependence as the means for change, but treatment must also focus upon the person and their social context if rehabilitation and reintegration are to become realistic and achievable goals for long term problem drug users.

The stage orientated model developed by Prochaska et al., (1992) commonly referred to as the 'cycle for change' has with good reason, dominated UK theory and practice with drug users, but combined with motivational interviewing (Miller \& Rollnick, 2002) the model risks an over emphasis upon the drug - there is a need to look beyond the drug. Concentrating upon individual motivation and psychological strategies for change are helpful and important components, but the discrimination, isolation and powerlessness faced by many problem drug users must be understood and incorporated within a social model of problem drug use.

* Thanks go to Lee Young who helped devise this model following many years of research we did together in Liverpool

\section{References}

Advisory Council on the Misuse of Drugs (1988) AIDS and Drug Misuse Part 1, London: HMSO.

Buchanan, J. (forthcoming 2005) Problem Drug Use in the 21st Century: A Social Model of Intervention in Social Work, in Health \& Mental Health, Heinonen T, \& Metteri A (eds.), Toronto: Scholars Press.

Buchanan, J. \& Young, L. (2000). The war on drugs; A war on drug users', in Drugs. education prevention \& policy, 7 (4), pp. $409-422$.

Bullock, T. (2003) Changing levels of drug use before, during and after imprisonment, in Prisoners' drug use and treatment: seven research studies edited by M. Ramsay, Home Office Research Study 267, pp. 23-49, London: Home Office.

Department for Education and Skills (2003) Improving Offenders' Learning and Skills Delivery Plan, 2003/04 - 2005/06, Nottingham: DfES Publications.

Drucker, E. (2000) 'From Morphine to Methadone; Maintenance Drugs in the Treatment of Opiate Addiction' in Harm Reduction National and International Perspectives, Incardia J A \& Harrison L D (eds), London: Sage pp. 27-45

European Monitoring Centre for Drugs and Drug Addiction (1999) Extended Annual Report of the Drug Problem in the European Union, Lisbon: EMCDDA

Home Office (2004) Reducing Re-offending National Action Plan, Home Office London: Communication Directorate

Home Office (2004a) Reducing Reoffending: National Action Plan, Reference Document July 2004 online report www.homeoffice.gov.uk/docs3/reoffending_contacts.pdf accessed on 31st July 2004

HM Treasury (2001) £300 Million Boost For Communities Against Drugs, Press Release, 49/01 09 April 2001, London: HMSO

Jones S., Drainey S., Walker, L. \& Rooney, J. (2004) Collecting the Evidence: Clients views on drug services, London: Addaction

Liriano, S. \& Ramsay, M. (2003) Prisoners' drug use before prison and the links with crime in Prisoners' drug use and treatment: seven research studies Edited by Malcolm Ramsay, Home Office Research Study 267, London: Home Office, pp. 6-22

Miller. W. \& Rollnick, S. (2002) Motivational Interviewing: Preparing People to Change.2nd Edition. New York: Guilford Press

Prochaska, J. O., DiClemente, C. C. \& Norcross, J. C. (1992). In Search of How People Change. Applications to Addictive Behaviors. American Psychologist, 47, pp. 1102-1113

Riley, D. \& O'Hare, P. (2000) 'Harm Reduction: History, Definition, and Practice' in Incardia J \& Harrison L (eds) Harm Reduction National and International Perspectives, London: Sage Publications.

Social Exclusion Unit (2002) Reducing re-offending by ex-prisoners, London: Crown Publications,

Social Exclusion Unit (2004) Tackling Social Exclusion: Taking stock and looking to the future - Emerging Findings, London: Crown Publications

Julian Buchanan is a Reader in Community Justice and member of the Social Inclusion Research Unit at University of Wales, NEWI, Wrexham, Wales, LL11 2AW. Tel: 01978293194 Email: j.buchanan@newi.ac.uk

This article was published in the Probation Journal: Buchanan J (2004) Missing Links: Problem Drug Use and Social Exclusion, Probation Journal Special Edition on Problem Drug Use Vol 51 No.4 pp.387-397 